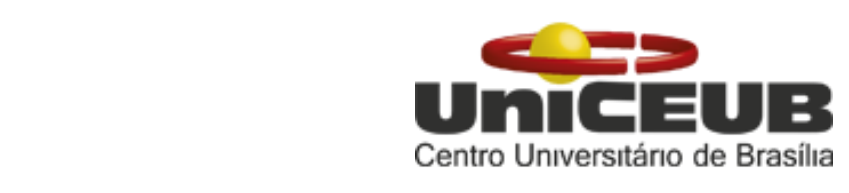

CENTRO UNIVERSITÁRIO DE BRASÍLIA - UniCEUB PROGRAMA DE INICIAÇÃO CIENTÍFICA

ITALO DE OLIVEIRA

\title{
ELETROESTIMULAÇÃO NEUROMUSCULAR PARA FORTALECIMENTO MUSCULAR DE RETO ABDOMINAL EM MULHERES
}

BRASÍLIA 2018 


\section{UnICEUB \\ Centro Unıversıtárıo de Brasilıa}

ITALO DE OLIVEIRA

\section{ELETROESTIMULAÇÃO NEUROMUSCULAR PARA FORTALECIMENTO MUSCULAR DE RETO ABDOMINAL EM MULHERES}

Relatório final de pesquisa de Iniciação Científica apresentado à Assessoria de Pós-Graduação e Pesquisa.

Orientação: Profa. Dra. Leticia Martins Paiva

\section{BRASÍLIA}




\section{DEDICATÓRIA}




\section{AGRADECIMENTO}

Agradeço primeiramente a Deus por ter me dado saúde, força e perseverança para superar as dificuldades enfrentadas, pois sem Ele eu nada sou.

A minha família que é minha base. Cada um exerceu papel fundamental para a finalização desse projeto, pois sempre estiveram ao meu lado me incentivando e me educando. Irrefutavelmente eles são os grandes formadores de minha identidade. Obrigado pelo amor, pelo exemplo e por confiarem na minha competência.

Assim como sou imensamente grato a todos meus amigos que me apoiaram nesse processo de aprendizagem e para quem eu recorria para me distanciar do trabalho.

Não poderia de deixar de agradecer a minha orientadora Professora Leticia Paiva, que acolheu e desenvolveu esse projeto junto comigo. Palavras não conseguem descrever o carinho que tenho por ti, obrigado pela seriedade e comprometimento em me auxiliar e me direcionar. Sempre encontrando soluções para os meus questionamentos e falhas. Sou grato pela paciência e incentivo.

E por último gostaria de agradecer a instituição do UniCEUB, por me proporcionar tamanha aprendizagem, estou finalizando meu curso e este projeto e posso dizer que tive o prazer de passar e conhecer o que é a tríade ensino, pesquisa e extensão. 


\title{
ELETROESTIMULAÇÃO NEUROMUSCULAR PARA FORTALECIMENTO MUSCULAR DE RETO ABDOMINAL EM MULHERES
}

\author{
Italo de Oliveira - UniCEUB, PIC Institucional, aluno bolsista \\ italooliveirafsa@sempreceub.com
}

\author{
Leticia Martins Paiva - UniCEUB, professor orientador \\ leticia.paiva@ceub.edu.br
}

A estimulação elétrica neuromuscular (EENM), também conhecida como corrente russa, é a aplicação da corrente elétrica para manter ou aumentar a força muscular. Como a fraqueza em reto abdominal é uma queixa frequente encontrada no sexo feminino, o objetivo deste estudo foi avaliar os efeitos da corrente russa em mulheres com déficit de força em abdômen, analisando se houve aumento da força, redução do percentual de gordura local e a intensidade da dor durante a aplicação do procedimento. Foram selecionadas dez mulheres, idade entre 18 a 40 anos, divididas em dois grupos: o grupo A foi composto por cinco mulheres sedentárias com fraqueza muscular em reto abdominal; e grupo B com cinco mulheres sedentárias com fraqueza em abdômen e que já tiveram pelo menos uma gestação. A EENM foi aplicada três vezes por semana, por 30 minutos, durante oito semanas, totalizando 24 sessões. As voluntárias foram avaliadas na $1^{\circ} \stackrel{0}{ } 12^{\underline{a}}$ e $24^{\underline{a}}$ sessão. As variáveis deste estudo foram: idade, tempo sem atividade física, índice de massa corporal (IMC), dobras cutâneas, perimetria, força muscular em abdômen e dor durante a aplicação da EENM. A análise estatística foi realizada pelo teste t-student, com nível de significância $p>0,05$. A idade média das participantes do grupo $A$ foi 23,6 anos e 27,6 anos para grupo B. O tempo médio sem praticar atividade física foi de 1,8 anos. $O$ valor médio do IMC encontrado entre as três avaliações foi de 23,6 para o grupo A e 24,7 para o grupo B. Houve no decorrer da pesquisa redução ou aumento de peso de algumas participantes. Quanto a força muscular não houve diferença significativa entre os grupos ( $p>0,05)$ : o grupo $A$ apresentou média de 3,5 de força muscular segundo o teste de Kendall, com mínimo de 3 e máximo 5 . E o $\mathrm{B}$ média de 3,6 conforme o mesmo teste, mínimo de 2 e máximo de 5 . A média da circunferência abdominal foi de $79 \mathrm{~cm}$ para o grupo A e $81,8 \mathrm{~cm}$ para o grupo $\mathrm{B}$, e das dobras cutâneas foi de $2,8 \%$ para o grupo $A$ e de $3,1 \%$ para o $B$, onde nenhum dos resultados comparativos apresentaram nível de significância. Com relação a escala visual analógica da dor a média foi de 2,2 em uma escala de zero a dez. Conclui-se que a utilização da estimulação elétrica neuromuscular mostrou resultados que justificam seu uso para fortalecimento do reto abdominal tanto em mulheres sedentárias quanto pós-gestacional, apesar de não apresentarem diferenças significativas entre os grupos. Quanto ao limiar de desconforto durante a aplicação da corrente foi possível notar que sua aplicação pode ser considerada tolerável.

Palavras-Chave: Eletroestimulação. Fisioterapia. Abdômen. Força Muscular 


\section{LISTA DE ABREVIAÇÕES}

cm: Centímetro

EENM: Estimulação elétrica neuromuscular

EVA: Escala visual analógica:

$\mathrm{Hz}:$ Hetz

IMC: Índice de massa corporal

kg: Quilogramas 


\section{LISTA DE FIGURAS}

FIGURA 1. Anatomia muscular da região abdominal

FIGURA 2. Diástase do musculo reto abdominal

FIGURA 3. Posicionamento dos eletrodos 


\section{LISTA DE TABELAS}

TABELA 1: Resultados Dobras cutâneas antes e após aplicação da EENM TABELA 2: Resultados Circunferência abdominal antes e após aplicação da ENNM TABELA 3: Resultados força muscular antes e após aplicação da EENM 


\section{SUMÁRIO}

$\begin{array}{ll}\text { INTRODUÇÃO } & 10\end{array}$

FUNDAMENTAÇÃO TEÓRICA

1.1 Sistema muscular e anatomia da região abdominal 11

1.2 Contração Muscular 13

$\begin{array}{lll}1.3 & \text { Corrente Russa } & 14\end{array}$

2. METODOLOGIA 17

3.RESULTADOS 20

4.DISCUSSÃO 22

5.CONSIDERAÇÕES FINAIS $\quad 24$

REFERÊNCIAS $\quad 25$

APÊNDICES A - Ficha de avaliação $\quad 28$

APÊNDICES B - Termo de Consentimento livre e esclarecido 30

ANEXOS A - Parecer Consubstancial do CEP 32 


\section{INTRODUÇÃO}

A procura pelo corpo ideal hoje é comparada a uma representação do sucesso. Considerando que a beleza é um fator que interfere no julgamento da sociedade, observa-se que algumas marcas naturais, como envelhecimento, herança genética e a fraqueza muscular levam a uma imagem corporal indesejada resultando em insatisfação e sentimentos negativos (VOESE et al., 2015).

$\mathrm{Na}$ última década foi considerável o aumento da busca de tratamentos estéticos não invasivos capazes de corrigir a aparência flácida da musculatura da região abdominal que acomete principalmente mulheres no pós-parto. Dessa forma, de acordo com Duarte e Mejia (2012), a busca pelo corpo perfeito por meio de técnicas de tratamento com resultados seguros e rápidos e sem alterar a rotina do dia a dia, é a opção mais desejada por ambos os sexos.

A fraqueza muscular quando afeta mulheres possui inúmeros desencadeantes como inatividade física, emagrecimento demasiado, envelhecimento e gravidez. Além do que após a terceira década de vida, inicia-se uma progressiva e contínua perda de massa muscular que passa a ser substituída por gordura e assim aumentando a incidência de fraqueza muscular. Dessa forma, a gordura localizada também é uma queixa recorrente nos consultórios de Fisioterapia Dermatofuncional e pode interferir sobre o bem-estar físico, psíquico e social dos pacientes (GUIRRO e GUIRRO, 2002; LIMA \& RODRIGUES, 2012).

Atualmente, a Estimulação Elétrica Neuromuscular (EENM) tem sido muito utilizada para tratamento da fraqueza muscular por ser um procedimento terapêutico não invasivo, rápido e que apresenta bons resultados (KLEFENS; DEON; MEDEIROS, 2013). Também conhecida como corrente russa, é uma corrente de média frequência aplicada para promover a contração muscular com finalidade de hipertrofia e aumento de força indicada para musculatura hipotônica e flácida (GUIRRO e GUIRRO, 2002; PERNAMBUCO, CARVALHO e SANTOS, 2013).

Diante do exposto, o objetivo deste estudo foi analisar os efeitos da corrente russa em mulheres no fortalecimento de reto abdominal em mulheres e alteração do percentual de gordura local, além de analisar a intensidade da dor durante a aplicação da técnica por meio da escala visual analógica (EVA). 


\section{FUNDAMENTAÇÃO TEÓRICA}

\subsection{Sistema muscular e anatomia da região abdominal}

O sistema muscular reveste totalmente o esqueleto e está preso aos ossos, sendo responsável pela movimentação do corpo e representam em média de 40 a $50 \%$ do peso corporal total (GUYTON e HALL, 2011). É dividido em três tipos: esquelético, cardíaco e liso; e possui quatro propriedades exclusivas que the permitem cumprir suas funções e contribuir de forma geral para a homeostasia do corpo. São elas: extensibilidade, contratilidade, irritabilidade e elasticidade (TORTORA, 2017; WIDMAIER et al.,2017). O músculo esquelético não se contrai na ausência de estimulação nervosa, pois necessita de potenciais de ação, e normalmente está sob o controle voluntário. (WIDMAIER et al.,2017).

$\mathrm{Na}$ anatomia muscular da região abdominal, ou parede abdominal compreende três unidades: músculo quadrado lombar, reto abdominal, musculo oblíquos abdominais (HARTWIG, 2008). Segundo Borges e Valentin (2002) Os músculos abdominais formam um apoio elástico de "quatro vias de estiramento" para o conteúdo abdominal. São elas o reto abdominal, o transverso do abdômen, oblíquo interno e oblíquo externo. Apresentados na figura 1.

Figura 1: Músculos da parede abdominal 


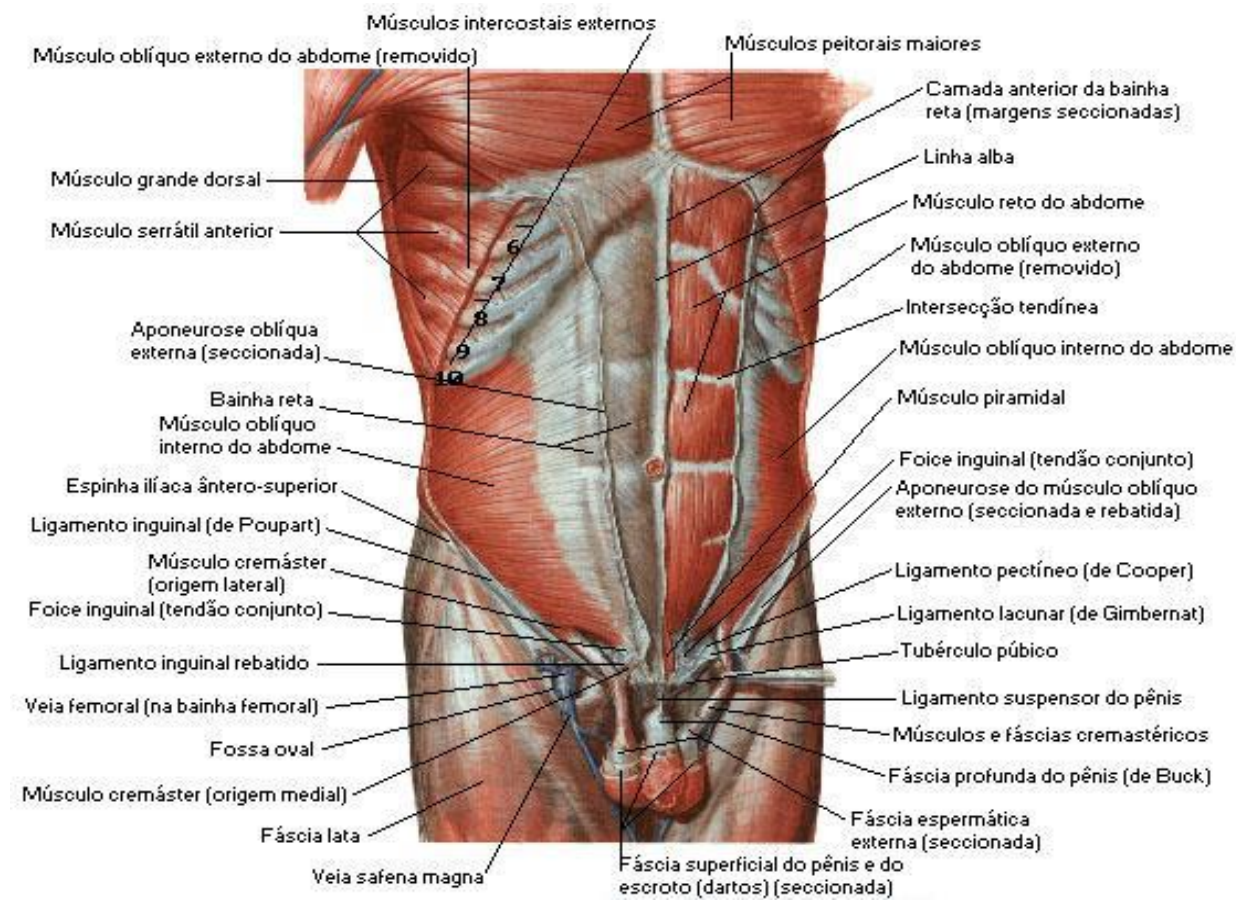

Fonte: NETTER, Frank H.. Atlas de Anatomia Humana. 2ed. Porto Alegre: Artmed, 2000.

O músculo reto do abdome é longo e se estende por toda a parede abdominal anterior, partindo da crista e sínfise púbica, inserindo-se nas cartilagens da $5^{\underline{a}}$ a $7^{\underline{a}}$ costelas e no processo xifoide do externo. A face anterior do músculo é interrompida por três faixas fibrosas transversas de tecido chamadas de intersecções tendíneas (TORTORA, 2017).

O músculo abdominal é responsável por realizar a flexão da coluna, sustentar a massa visceral, auxiliar na defecação, na expiração e na gestação, além de auxiliar na micção e trabalho de parto (BORGES; VALENTIN, 2002).

Durante o período gestacional ocorre o estiramento da musculatura abdominal, definida como diástase do músculo reto abdominal que é a separação dos dois músculos que constituem o reto abdominal, ao longo da linha alba (LEITE; ARAUJO, 2012). Borges e Valentin (2002) aludem que esse estiramento deixam um espaço de mais ou menos 1 a $3 \mathrm{~cm}$ entre os dois ventres do músculo ao final da gestação e ocorre predominantemente em mulheres multíparas, obesas, com musculatura abdominal flácida e fraca. É fato que a gestação pode então ocasionar essa alteração funcional indolor ou desencadear uma flacidez abdominal no pósparto (DEMARTINI, et. al , 2016). Ambas situações são indicativas de realização de tratamento de eletroestimulação neuromuscular local. 
Figura 2: Diástase do musculo reto abdominal

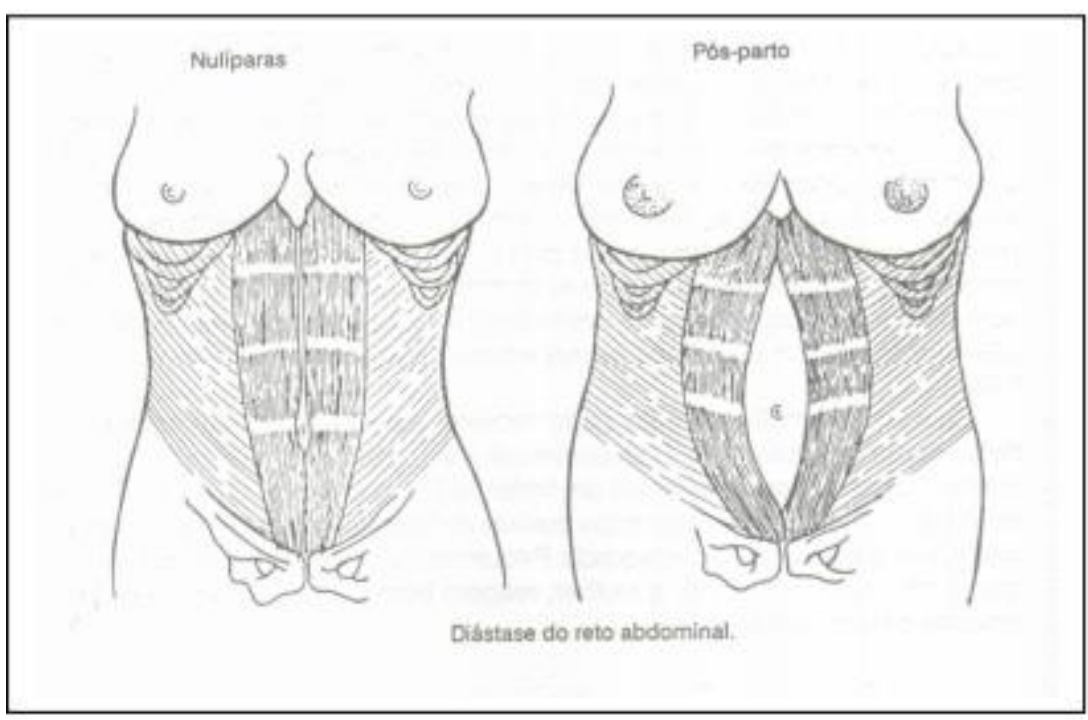

Fonte: POLDEN; MANTLE, 2000

\subsection{Contração Muscular}

Segundo WIDMAIER et al. (2017) contração refere-se meramente à ativação dos locais geradores de força dentro das fibras musculares - as pontes cruzadas de actina e miosina, sendo ativadas por fibras nervosas motoras. O sistema nervoso é então encarregado por proporcionar o estimulo que é enviado através dos nervos periféricos para o músculo estriado, ocasionando a contração muscular (DANUT, 2015).

Figueira e Meija (2014) aponta que na região que se localiza o citoplasma da fibra muscular esquelética existe muitas miofibrilas contráteis, constituídas por actina e miosina. A contração do músculo esquelético se dá de maneira voluntária e ocorre pelo deslizamento dos filamentos de actina sobre os de miosina.

Para Guyton e Hall (2011) a contração muscular realiza-se em fases que são descritas a seguir: um potencial de ação é produzido e difundido pelos nervos motores até chegar nas fibras musculares; dessa maneira sucede a liberação do neurotransmissor acetilcolina pelos nervos motores; assim ocorre a liberação dos canais de cátions regulados pela acetilcolina; para dessa maneira acontecer a difusão de íons sódio para o interior das fibras musculares causando a despolarização local desencadeando o potencial de ação. Por fim o despolarizando 
o que acaba por fazer com que o retículo sarcoplasmático libere grande quantidade de íons cálcio, ativando os filamentos de miosina e actina, promovendo 0 deslizamento de um sobre o outro.

Comumente a contração muscular pode ser classificada três tipos: isotônica, isométrica e isocinética (FLECK, 2006). A isotônica é a que mais se diverge das demais por se subdividir em concêntrica e excêntrica. Na concêntrica a origem e a inserção muscular se integram durante o movimento; e na excêntrica verifica-se o deslocamento da origem e inserção muscular. $\mathrm{Na}$ isométrica os segmentos articulares não são mobilizados, porém é observa-se a contração do músculo. E na isocinética a contração ocorre com velocidade angular continua (FLECKS, 2006; LIPPERT, 2010).

Robertson (2012) afirma que no momento em que se utiliza a EENM na musculatura esquelética, há uma diferenciação na contração voluntária em alguns aspectos devido a ordem de recrutamento: Primeiro as fibras nervosas motoras de diâmetro maior são ativadas antes das de menor diâmetro; assim como a distância dos eletrodos da fibra nervosa devido a ordem de recrutamento não ocorrer na sequência da contração voluntaria. Ou seja, as unidades motoras acabam não sendo ativadas no mesmo instante de tempo e na mesma frequência.

\subsection{Corrente Russa}

Segundo GUIRRO e GUIRRO (2002) a EENM é a aplicação da corrente elétrica que visa promover uma contração muscular. É um estimulador no qual apresenta uma saída continua formada por pulsos de do tipo retangular ou senoidal, bipolar, simétrica, emitidos na frequência de 2.500 hertz modulada por uma onda que pode variar de 50 a 80 hertz (NELSON, 2003; BRIEL, 2003; LIMA; RODRIGUES, 2012).

Esta é uma técnica fisioterapêutica utilizada para fins de fortalecimento muscular desenvolvida em meados da década de 70 que se difundiu nas clinicas fisioterapêuticas do mundo inteiro, sobretudo nas de estéticas usada como ferramenta para combater a atrofia muscular ou minimizar a efeitos apresentados pela fraqueza muscular (NELSON, 2003; BRIEL, 2003; LIMA; RODRIGUES, 2012). 
No ano de 1977 um pesquisador soviético chamado Yakov Kots divulgou resultados de trabalhos que se tratava de uma corrente $2500 \mathrm{~Hz}$. Esta foi utilizada para aumento de força muscular na contração voluntária máxima (CVM) em atletas de elite em ate $40 \%$. Kots após a divulgação do seu trabalho abriu as portas para a pratica da EENM combinada com a contração muscular voluntária ou sozinha, desta maneira ficando conhecido como pai da corrente russa (BORGES et al., 2007).

Conforme alguns estudos a EENM é indicada para promover ativação circulatória, aumento do trofismo muscular, recuperar a sensação de contração muscular nos casos de perda de sinestesia, melhorar o rendimento físico em esportes de alto nível, melhorar a estabilidade articular, tratamento de disfunções posturais, utilização no pré e pós-operatório devido ao período de imobilização, minimizar a flacidez muscular, aumentar ou manter a força muscular, dentre outros. (SORIANO, PÉREZ e BAQUÉS, 2000; AGNE, 2004; BORGES, EVANGELISTA e MARCHI, 2006)

Dentre as indicações supracitadas, depreende-se que o músculo sofre adaptações fisiológicas e bioquímicas quando é submetido à eletroestimulação. Dentre essas adaptações, cita-se a hipertrofia muscular, aumento da irrigação sanguínea e do retorno venoso e linfático, aumento da atividade oxidativa da mioglobina, mitocôndrias e do número de capilares, fazendo com que ocorra a transformação temporária das fibras musculares tipo II fásicas (brancas), para tipo I tônicas (vermelhas) (AGNES, 2004).

Todavia, para obter esses resultados a corrente aplicada deve ser de elevada amplitude e poucas repetições, modulando a frequência de 50 a $150 \mathrm{~Hz}$ para estimular fibras musculares fásicas, e 20 a $30 \mathrm{~Hz}$ para eletroestimular as fibras musculares tônicas (PEREIRA, 2007).

Segundo Sousa (2016), a faixa de frequência terapêutica do organismo humano é de 1 à $200 \mathrm{~Hz}$, quando se refere à corrente elétrica excitomotora. Fora disso, o organismo não trabalha, portanto não existe terapia. Por isso, não adianta aplicar frequências mais elevadas.

De acordo com os ganhos de benefícios citadas por (PEREIRA, F. 2007; HOOGLAND ,1988) destaca-se que a utilização da EENM consegue ativar $30 \%$ a $40 \%$ a mais das unidades motoras com a estimulação russa que nos exercícios 
comuns e tratamentos convencionais, além de aumentar a força muscular a curto prazo. Entretanto essa informação ainda é muita utilizada em livros e artigos e apresenta bastante divergências no que concerne aos programas de eletroestimulação.

Borges (2010) afirma que esses ganhos são possíveis com (EENM) pois ela consegue ativar unidades motoras necessárias para uma contração muscular efetiva, devido a (EENM) pode fazer quase todas as unidades motoras se contraírem sincronizadamente em um musculo, dessa maneira permitindo contrações voluntarias mais fortes. Porem autores como SILVA et al (2015) e DANTAS et al (2015) dizem em seus trabalhos que a corrente russa induz menor torque comparada a outras modulações e não gera mais torque que o exercício resistido.

A partir disso é notório que utilização dessa técnica é capaz de trabalhar toda musculatura, inclusive zonas consideradas difíceis de serem atingidas com outros tratamentos. Diante do exposto percebesse que a EENM tem proporcionado resultados satisfatórios em tratamentos estéticos, principalmente no que diz respeito ao fortalecimento muscular (RIBAS et al., 2011). Tendo como objetivo principal a hipertrofia, uma vez que o número de pessoas que tem procurado uma forma alternativa de fortalecimento, com finalidade estética tem aumentado a cada dia. 


\section{METODOLOGIA}

Trata-se de um estudo de caráter descritivo e intervencional, realizado no laboratório de eletrofototerapia do Centro Universitário de Brasília - UniCEUB, desenvolvido nos meses de fevereiro a julho de 2018 e obedeceu a todas as recomendações da Resolução n. 466/12 do Conselho Nacional de Saúde. O protocolo de pesquisa foi aprovado pelo comitê de Ética em Pesquisa em Humanos do Centro Universitário de Brasília (CEP/UniCEUB) com CAAE n. 75055617.0.0000.0023.

Para a participação na pesquisa, os voluntários deveriam atender aos seguintes critérios de inclusão: Ser do gênero feminino, ter idade entre 18 e 40 anos, sedentárias, que apresentam fraqueza muscular do reto abdominal, e assinar o Termo de Consentimento Livre e Esclarecido (TCLE).

Foram excluídas voluntárias com obesidade (IMC > 30), gravidez ou suspeita, hematoma e/ou escoriações na região abdominal, dores pélvicas e ou abdominais; deficiência ou ausência de sensibilidade cutânea, presença de marcapasso, processo infeccioso e ou inflamatório, neoplasia, febre, ausência em qualquer uma das sessões de eletroestimulação, força muscular grau 5 em abdome.

Participaram da pesquisa 10 voluntárias, do sexo feminino, divididas em dois grupos distintos, onde o grupo A foi composto por 5 mulheres sedentárias com fraqueza muscular do reto abdominal e o grupo B por 5 mulheres sedentárias com fraqueza muscular do reto abdominal pós-gestacional.

Antes da aplicação do protocolo, as participantes foram submetidas há uma avaliação inicial onde foram obtidos as seguintes variáveis: relação peso-altura (IMC), medida das dobras cutâneas (adipometria), medida da circunferência da região umbilical, graduação de força muscular pelo teste de kendal e tempo sem praticar atividades física.

Para a realização da avaliação todas as participantes ficaram com os pés descalços e vestindo roupas leves como top e shorts. Para determinação da estatura, utilizou-se um estadiômetro com as participantes em pé, de forma ereta, com os membros superiores pendentes ao lado do corpo, os pés unidos e as superfícies posteriores dos calcanhares, nádegas, cintura escapular e região occipital em contato com a escala de medida. 
Para verificação do peso corporal foi empregada a utilização de uma balança antropométrica com precisão de $100 \mathrm{~g}$. As participantes foram orientadas pelo avaliador a se posicionar de pé, no centro da plataforma da balança, em posição ereta, de costas para a escala de medida, com os membros superiores pendentes ao lado do corpo, os pés afastados à largura dos quadris, o peso do corpo distribuído em ambos os pés e olhar voltado para o horizonte.

As circunferências foram realizadas mediante utilização de uma fita antropométrica de aço flexível com precisão de uma casa decimal. As medidas das dobras cutâneas com adipômetro, modelo analógico, e para graduação da força muscular foi solicitado que as participantes deitasse na maca em decúbito dorsal com quadris e joelhos estendidos, e realizar a flexão da coluna vertebral em três fases: com as mãos atrás da cabeça, com braços cruzados sobre o tórax e com os braços estendidos para a frente.

As voluntárias foram submetidos a essa avaliação supracitada na $1^{\circ}$ e $24^{\underline{a}}$ sessões para fins de comparação do estudo. Para a corrente russa sobre o músculo reto abdominal, realizaram-se 24 sessões, onde cada uma teve duração de 30 minutos, três vezes por semana, durante oito semanas, por dois meses.

Para as sessões de eletroestimulação, utilizou-se um equipamento Neurodyn Hight Volt (Ibramed geração 2000) com 6 canais e ajustado os seguintes parâmetros no protocolo de atendimento com frequência de pulso de $50 \mathrm{~Hz}$; tempo de subida/descida de 3/3 segundos; tempo de contração/relaxamento de 9/9 segundos, respectivamente. A intensidade utilizada foi a máxima suportada por cada uma das participantes do estudo. Este protocolo foi adaptado dos estudos de Pernambuco, Carvalho \& Santos (2013) e Sacilotto et al (2017).

Para a aplicação da (EENM), inicialmente efetuou-se assepsia local de abdômen com álcool $70 \%$. Durante o procedimento de estimulação, todas as participantes permaneceram em decúbito dorsal, com flexão dos quadris e joelhos, e com os pés apoiados sobre a maca. A estimulação foi proporcionada por quatro eletrodos auto adesivos (dois canais), sendo dois eletrodos colocados na porção superior do reto abdominal, sobre o ponto motor identificado manualmente e outros dois na porção média do mesmo músculo, procedimento realizado bilateralmente. Todo protocolo de posicionamento e aplicação da corrente foi baseado no estudo de Pernambuco, Carvalho \& Santos (2013). 
Utilizou-se a Escala Visual Analógica (EVA) para medir o desconforto sensorial durante a aplicação da corrente russa. No momento em que a intensidade máxima da corrente tolerada foi percebida, a participante apontava o nível máximo de desconforto provocado pelo estímulo fornecido, em uma escala de "ausência total de desconforto" (valor 0 ) e "desconforto máximo tolerável" (valor 10).

Figura 3: Posicionamento dos eletrodos

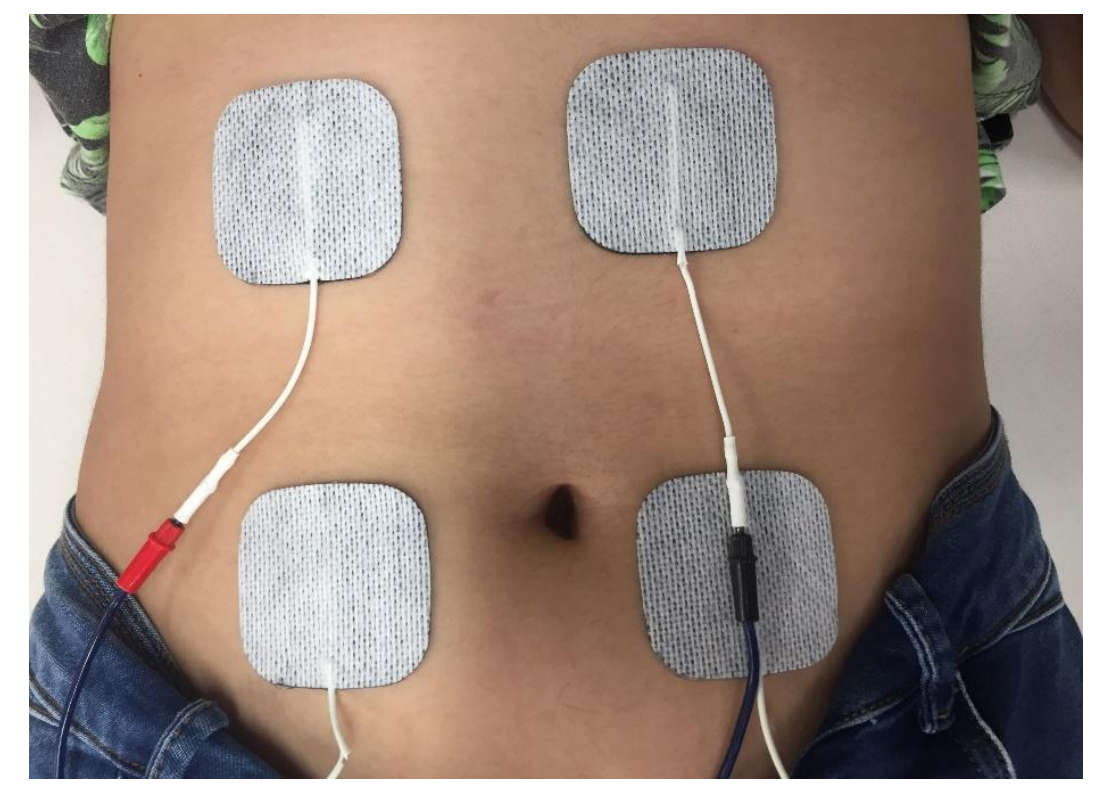

Fonte: Autores da pesquisa, 2018.

Para a análise dos dados, utilizou-se o Software estatístico BioEstat 5.4. As variáveis quantitativas foram apresentadas em seus valores mínimo e máximo, média, mediana e desvio padrão. Ainda utilizou os testes: teste t de Student para analisar a diferença dois grupos independentes e para todos os procedimentos 0 nível de significância foi considerado $5 \%(p>0,05)$. 


\section{RESULTADOS}

A idade média das participantes da pesquisa foi 23,6 no grupo $A$ e 27,6 no grupo B. Quanto ao IMC o grupo A apresentou valor médio do IMC de 23,6 ( $d p=3,0814)$ e o valor médio de IMC para o grupo B foi de $24,7(d p=2,3503)$. Sendo importante salientar que algumas participantes ao decorrer da pesquisa tiveram variação de peso, ressalta-se que todas participantes foram orientadas a alimentarse normalmente. Dessa maneira sua análise para essa pesquisa se torna irrelevante, pois está variação de peso pode estar associada a diversos fatores e variáveis.

Quanto ao tempo médio sem realizar atividade física, ambos grupos apresentaram 1,8 anos, mínimo 1 ano e máximo 3 anos sem realizar atividades físicas.

$\mathrm{Na}$ tabela 1 está disposta os dados de percentual de gordura (dobras cutâneas) que não demostra diferença significativa entre a primeira avaliação e a última avaliação, tal achado esta provavelmente associado a não pratica de exercício físicos.

Tabela 1: Resultados Dobras cutâneas antes e após aplicação da EENM

\begin{tabular}{|c|c|c|c|c|c|}
\hline \multicolumn{3}{|c|}{ Grupo A } & \multicolumn{3}{|c|}{ Grupo B } \\
\hline Voluntárias & Antes & Depois & Voluntárias & Antes & Depois \\
\hline A) & $3 \%$ & $3 \%$ & A) & $3,2 \%$ & $3,2 \%$ \\
\hline B) & $3,8 \%$ & $3,8 \%$ & B) & $3 \%$ & $3 \%$ \\
\hline C) & $2,5 \%$ & $2,5 \%$ & C) & $3,6 \%$ & $3,6 \%$ \\
\hline D) & $3,7 \%$ & $3,7 \%$ & D) & $4,8 \%$ & $4,5 \%$ \\
\hline E) & $3,8 \%$ & $3,8 \%$ & E) & $3,9 \%$ & $3,9 \%$ \\
\hline
\end{tabular}

Média: 2,8

Média: 3,2 
Na tabela 2 circunferência abdominal antes e após aplicação da ENNM é possível notar a redução de medidas da primeira avaliação para a última avalição, principalmente no grupo B. Porem apesar de tais achados estatisticamente não houve diferença significativa.

Tabela 2: Resultados Circunferência abdominal antes e após aplicação da ENNM

\begin{tabular}{|lcc|ccc|}
\hline \multicolumn{3}{|c|}{ Grupo A } & \multicolumn{4}{c|}{ Grupo B } \\
\hline Voluntárias & Antes & Depois & Voluntárias & Antes & Depois \\
\hline A) & 63 & 62 & A) & 70 & 68 \\
\hline B) & 97 & 96 & B) & 74 & 70 \\
\hline C) & 65 & 65 & C) & 75 & 73 \\
\hline D) & 90 & 88 & D) & 98 & 94 \\
\hline E & 84 & 77 & E) & 98 & 97 \\
\hline
\end{tabular}

Média: 79,0667

Média: 81,8

Ao ser analisado força muscular, ambos os grupos apresentaram aumento de força muscular, porém não houve diferença significativa entre os grupos $(p>0,05)$ (Tabela 3).

Quanto a dor ou desconforto sensorial ao ser aplicado a EVA a média foi de 2,2 .

Tabela 3: Resultados força muscular antes e após aplicação da EENM

\begin{tabular}{|ccc|ccc|}
\hline \multicolumn{3}{c}{ Grupo A } & \multicolumn{4}{c|}{ Grupo B } \\
\hline Voluntárias & Antes & Depois & Voluntárias & Antes & Depois \\
\hline A) & 4 & 4 & A) & 3 & 5 \\
\hline B) & 3 & 4 & B) & 4 & 5 \\
\hline C) & 3 & 4 & C) & 3 & 4 \\
\hline D) & 3 & 4 & D) & 3 & 4 \\
\hline E) & 4 & 5 & E) & 2 & 3 \\
\hline \multicolumn{2}{r|}{ Média: 3,5333} & & & Média: 3,6 & \\
\hline
\end{tabular}

p: significância estatística 


\section{DISCUSSÃO}

O presente estudo evidenciou que, mesmo sem resultados significativos, a utilização da corrente russa é capaz de aumentar a força muscular de indivíduos sedentárias e sedentárias pós-gestacional que apresentam fraqueza da região abdominal. OLIVEIRA, B; JACINTA, E; MARTINS, T. (2015) desenvolveram um estudo com mulheres sedentárias comparando duas correntes sendo uma delas a corrente russa, concluíram que apesar dos resultados não apresentarem ganho significativo de força muscular, também houveram aumento de força, corroborando com os resultados encontrados nessa pesquisa.

Ribas et al., (2011) realizaram um estudo com 8 mulheres separadas em dois grupos, onde o grupo A foram submetidas a quinze sessões de corrente russa $\mathrm{e}$ grupo $B$ não submetidas à corrente russa. Concluiram que apesar dos resultados obtidos com o grupo que realizou a EENM serem superiores ao do outro grupo, o mesmo não revelou dados significativos, provavelmente, devido ao tamanho reduzido das amostras. Tal informação é de extrema importância uma vez que o este presente estudo também apresentou uma amostra de tamanho reduzido, ressaltando a importância de se realizar estudos com amostras maiores.

Quando analisado os resultados da circunferência abdominal é possível notar que o grupo $B$ desde estudo tiveram redução de suas medidas após as sessões de corrente russa. De acordo com Borges e Valentim (2002) em seu estudo de caso realizado com 3 mulheres pôs gestacional aplicando a EENM, o mesmo alude que o tratamento utilizando tal ferramenta pode reduzir medidas pelo encurtamento do reto abdominal em sua dimensão longitudinal. E Borges (2010) afirma que a aplicação da EENM pode ter sua eficácia reduzida se houver acúmulo de gordura da região abdominal.

Maciel (2010), em seu estudo que havia como objetivo verificar a influência da EENM de média frequência na força e massa muscular de indivíduos saudáveis. Concluiu que todos os participantes apresentaram aumento de força muscular e um expressivo aumento das doses de corrente utilizada (intensidade), porém não obtiveram alteração expressiva quanto à massa muscular (perimetria) e quanto ao percentual de gordura corporal.

Em comparação com o nível de dor ou desconforto da EENM corroboram com as informações de Modesto (2014) na qual o autor afirma que o desconforto 
eliciado pela EENM está ligado mais diretamente à largura de pulso das correntes, e que a utilização da intensidade deve-se levar em consideração as características individuais do paciente.

Dessa maneira essas informações são fundamentais para direcionar o uso correto da EENM dentro do ambiente clinico, especialmente na fisioterapia dermatofuncional dessa maneira promovendo resultados mais satisfatórios com o uso desse recurso. 


\section{CONSIDERAÇÕES FINAIS}

Conclui-se que a utilização da Estimulação Elétrica Neuromuscular mostrou resultados que justificam seu uso para fortalecimento do reto abdominal em mulheres sedentárias e mulheres sedentárias pós-gestacional, apesar de não apresentarem diferenças significativas entre os grupos.

Em relação ao limiar de desconforto ou dor durante a aplicação da estimulação elétrica neuromuscular foi possível notar que sua aplicação é tolerável. Propõe-se que novos estudos sejam realizados, uma vez que reconhece as limitações do presente estudo principalmente devido ao tamanho da amostra. 


\section{REFERÊNCIAS}

AGNE JE. Eletrotermoterapia teoria e prática. Santa Maria: Orium, 2004

BORGES, F. S.; VALENTIN, E. C. Tratamento da flacidez e diástase do reto abdominal no puerpério de parto normal com o uso de eletroestimulação muscular com corrente de média frequência - estudo de caso. Revista Brasileira de Fisioterapia Dermato-Funcional. v.1, n.1. 2002.

BORGES, F.; Dermato Funcional: Modalidades Terapêuticas nas Disfunções Estéticas. 2. ed., São Paulo: Editora Phorte, 2010.

BORGES, Fábio dos $S$. et al. Parâmetros de modulação na eletroestimulação neuromuscular utilizando corrente russa: Parte 2. Revista Fisioterapia Ser, a. 2, n. 2, abr.jun. 2007.

BRIEL AF, P. MF.; Lopes, LG. Influência da corrente russa no ganho de força e trofismo muscular dos flexores no antebraço não dominante. Arq Cienc Saúde Unipar 2003; 7(3):205-210

DA SILVA V.Z M, DURIGAN JLQ; ARENA R, et al. Current evidence demonstrate similar effects of Kilohertz-frequency and low-frequency current on quadriceps evoked torque and discomfort in healthy individuals: A systematic review with metaanalysis. Physiother Theory Pract. 2015; 31: 533-539.

DEMARTINI, ELAINE et al. Diastasis of the rectus abdominis muscle prevalence in postpartum. Fisioter. mov., Curitiba, v. 29, n. 2, p. 279-286, June 2016.

DUARTE, A. B.; MEJIA, D. P. M. A utilização da Radiofrequência como técnica de tratamento da flacidez corporal. Pós-graduação em Fisioterapia DermatoFuncional - Faculdade Ávila, 2012

FLECK, S. J.; KRAEMER, W. J. Fundamentos do treinamento de força muscular. Tradução Jerri Luiz Ribeiro. 3. ed. Porto Alegre: Artmed, 2006.

FIGUEIRA, MEJIA, O benefício de corrente russa no tratamento de flacidez muscular, FAIPE,faculdade Sul Americana , pós graduação de fisioterapia. 2014 GUIRRO, E. C. O. GUIRRO, R. R. Fisioterapia Dermato-Funcional: fundamentos, recursos e patologias. 3 ed. São Paulo: Manole, 2002.

GUYTON, A. C.; HALL, J. E. Tratado de fisiologia médica. 12 ed. Elsevier, 2011. HARTWING, WALTER C. Fundamentos em anatomia. São Paulo: Artmed Editora S.A , 2008. 
HOOGLAND, R. Strengthening and stretching of muscles using electrical current B.V. Enraf Nonius. Delf, Holanda, p.1-14, 1988.

KLEFENS, S. O. ; DEON, K. C.; MEDEIROS, T. Uso da estimulação elétrica neuromuscular no manejo da diástase de reto abdominal pósgestacional: Relato de caso. Revista UNIANDRADE: Paraná; 12(3): 241-249, 2013.

LEITE, ANA CRISTINA N MARINHO TORRES;; ARAUJO, KATHLYN KAMOLY B CAVALCANTI.Diástase dos retos abdominais em puérperas e sua relação com variáveis obstétricas. Fisioter. mov., Curitiba, v. 25, n. 2, p. 389-397, June 2012. LIMA, E.; RODRIGUES, G. A estimulação russa no fortalecimento da musculatura abdominal. ABCD - Arquivos Brasileiros de cirurgia digestiva, São Paulo, v.25, n.2, p.125-128, Jun. 2012.

LIPPERT, L. S. Cinesiologia clínica e anatomia. 4. ed. Rio de Janeiro:Guanabara Koogan, 2010.

L. OGURA DANTAS, A. VIEIRA, A. L. JUNIOR, T.F. SALVANI, J.L. DURIGAN Comparison between the effects of four different electrical stimulation current waveforms on isometric knee extension torque and perceived discomfort in healthy women Muscle Nerve, 51 (2015), pp. 76-82

Maciel, Fábio. (2010). Efeitos da corrente russa no ganho de força muscular. Fisioterapia Ser 1809-3469. 05. 226 - 229.

MODESTO, Karenina Arrais Guida. Desconforto sensorial na estimulação elétrica neuromuscular em correntes de média e baixa frequência. 2014.

NETTER, F. H. Atlas de Anatomia Humana. 2 ed. Porto Alegre: Artmed, 2000.

NELSON RM,HAYES KW, CURRIER DP. Eletroterapia Clínica. 3aㅡ ed. Barueri: Manole; 2003

OLIVEIRA, B; JACINTA, E; MARTINS, T. Comparação entre a corrente russa e a FES no fortalecimento de mulheres sedentárias. 2015. $61 \mathrm{f}$. Monografia - Curso de Fisioterapia, Centro Universitário católico Salesiano Auxilium, São Paulo, 2015. PERNAMBUCO, A.P.; CARVALHO, N.M.; SANTOS, A.H. A eletroestimulação pode ser considerada uma ferramenta válida para desenvolver hipertrofia muscular? Fisioter Mov. 2013;26(1):123-31.

POLDEN, M.; MANTLE, J. Fisioterapia em ginecologia e obstetrícia. $2^{a}$ ed. São Paulo: Santos, 2000

PEREIRA, F. Eletroterapia sem mistérios - Aplicação em estética facial e corporal . 3ed Rio de Janeiro: Editora Rubio, 2007 
RIBAS, T.F. et al. Avaliar os efeitos da corrente russa na região glútea como coadjuvante na atividade física com finalidade estética. Ágora: Revista de Divulgação Científica, v. 18, n 2, p. 53-63, dez. 2011.

ROBERTSON, V. Eletroterapia Explicada: Princípios E Prática ; 4ED. [S.I.]: Rio de Janeiro Elsevier 2012.

ROCKENBACH, J. Estimulação elétrica neuromuscular no tratamento da diástase abdominal: uma revisão de literatura. 2012. 17 f. Monografia - Universidade Regional do Noroeste do Estado do Rio Grande do Sul - UNIJUÍ, Rio Grande do Sul, 2012.

SACILOTTO, M. C. B.; LAVAGNOLI, C. F. R.; SILVEIRA-FILHO, L. M.; et al. Um protocolo mais simples de eletroestimulação neuromuscular periférica melhora a capacidade funcional de pacientes com insuficiência cardíaca grave. Int $\mathbf{J}$ Cardiovasc Sci. 2017;30(6):484-95.

SOUSA, E. F. Efeitos da Eletroestimulação Neuromuscular em pacientes críticos: uma revisão de literatura. 2016. 49f. Tese (Aprimoramento) - Faculdade de Medicina de Ribeirão Preto, Universidade de São Paulo, Ribeirão Preto, 2016. TORTORA, G. J. Corpo humano : fundamentos de anatomia e fisiologia. 2017. VOESE, F; KLEINPAUL, W; PETRY, A. Esthetic plastic surgery: Experiencies concerning corporal (re)constructions and implications for nursin. Northeast Network Nursing Journal, Fortaleza, v.16, n.2, p.185-193, Mar./Abr. 2015.

WIDMAIER,E.P; RAFF, H. STRANG,K.T VANDER. Fisiologia humana: os mecanismos das funções corporais. 14 ed- Rio de Janeiro: Guanabara Koogan, 2017 


\section{APÊNDICES A - Ficha de avaliação}

ANEXO2 - ANAMNESE

AVALIACÃO FISIOTERAPÊUTICA

Data: _ I I

Nome:

Idade: Data de nascimento:

Gênero:

Cor:

Peso:

Altura: Estado Civil:

Profissão:

Telefone: ()

Tempo sem praticar atividades fisicas:

Quantidade de filhos:

Tipo de parto:

Sinais Vitais

P.A:

F.R:

FC:

SAT:

TAX:

Inspeção:

Palpação

Circunferência abdominal:

IMC:

Dobras Cutâneas (Abdômen):

Dor: ( ) Presente () Ausente

Escala Visual Analógica ( EVA): 
O

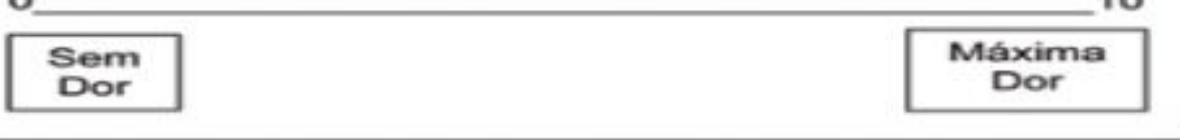

Figura 1 - Escala Visual Analógica (EVA) de 10 cm para avaliacelo da intersidade da dor no primeiro apoio matinal.

Teste de força - Kendall

\begin{tabular}{|c|c|}
\hline & Inicial: \\
\hline & $\begin{array}{l}\text { ( ) Grau Nermal: A pessoa estí com as màes atrás da cabeça, realiza a } \\
\text { fexâo da coluna vertebral, mantêm esta fletida, eaquanto passa para a fase } \\
\text { de flexâe do quadril e completa o mevimente. }\end{array}$ \\
\hline & $\begin{array}{l}\text { ( ) Grau Bem: A pessoa está cem os braços cruzades sobre o tórax, realiza } \\
\text { a flexảo da coluna vertebral, mantêm esta fletida, enquanto passa para a fase } \\
\text { de fexảo do quadril e completa o mevimento. }\end{array}$ \\
\hline & $\begin{array}{l}\text { ( ) Grau Regular: A pessea está cem es braçes estendides para a frente, } \\
\text { realiza a flexhio da coluna vertebral, mantèm esta fletida, enquanto passa } \\
\text { para a fase de fexas de quadril e completa e movimenta. }\end{array}$ \\
\hline & 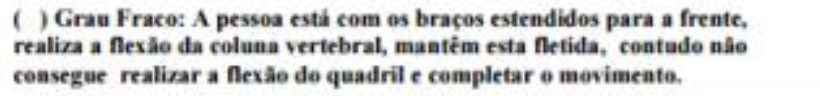 \\
\hline & Final: \\
\hline & $\begin{array}{l}\text { ( ) Grae Nermal: A pessoa está com as mâos atrás da cabeça, realiza a } \\
\text { fexâo da coluna vertebral, mantèm esta fetida, ençuanto passa para a fase } \\
\text { de flexảo do quadril e completa o mevimento. }\end{array}$ \\
\hline & $\begin{array}{l}\text { ( ) Grau Bean: A pessoa está cem es braços cruzades sobre o tórax, realiza } \\
\text { a fexåo da celuaa vertebral, wantêm esta fetida, enquanto passa para a fase } \\
\text { de flexảo do quadril e completa a mevimento. }\end{array}$ \\
\hline & 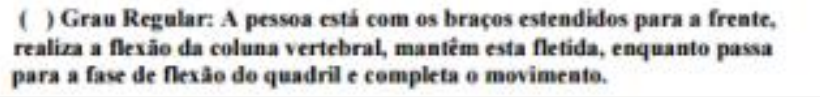 \\
\hline 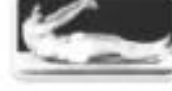 & $\begin{array}{l}\text { ( ) Grau Frace: A pessea estí com os braços estendides para a frente, } \\
\text { realiza a flex he da coluna vertebral, mantèm esta fletida, contude năo } \\
\text { coasegue realizar a flexâe do quadril e completar o movimente. }\end{array}$ \\
\hline
\end{tabular}

Observações do teste: 


\title{
APÊNDICES B - Termo de Consentimento livre e esclarecido
}

\author{
ANEXO 1 - TERMO DE CONSENTIMENTO LIVRE E ESCLARECIDO \\ CENTRO UNIVERSITÁRIO DE BRASÍLIA - UniCEUB
}

Pesquisador: Italo de Oliveira

Convido-o para participar do presente estudo sobre, UTILIZAÇÃo DA ELETROESTIMULAÇÃO NEUROMUSCULAR EM MULHERES COM FRAQUEZA MUSCULAR DE RETO ABDOMINAL mas antes de decidir se deseja participar, você deverá ler e compreender todo o conteúdo abaixo. A equipe deste estudo responderá às suas perguntas a qualquer momento (antes, durante e após o estudo). Ao final, caso decida participar, você será solicitado a assinar este termo e receberá uma cópia do mesmo. Para avaliação dos resultados será utilizado, estimulação elétrica neuromuscular (EENM) que é uma corrente de média frequência capaz de promover uma contração muscular com finalidade de ganhar força e aumentar o volume muscular. Além da utilização da EENM será mensurado o índice de massa corporal (IMC), gordura abdominal através do adipômetro $(\% \mathrm{G})$ , força muscular através do teste de Kendal e nível de desconforto através da Escala visual analógica (EVA).

As informações obtidas neste estudo, por meio dos resultados de todos os testes, serão utilizadas exclusivamente como dados de pesquisa científica, podendo ser publicados e divulgados, sendo resguardada a identidade e privacidade dos participantes

Você poderá recusar a participação e/ou desistir durante o processo, sem que isso lhe cause qualquer constrangimento nem penalidade.

Em princípio é necessário salientar que a realização do presente estudo apresenta risco mínimo ao individuo. Quanto relacionado à aplicação da corrente russa o paciente poderá sentir algum nível de desconforto sensitivo e dor durante a aplicação da corrente que será analisado através da escala visual analógico (EVA), assim como sensação de fadiga muscular após aplicação da corrente devido a EENM .O estudo atende a preceitos da ética em pesquisa com seres humanos, bem como à legislação brasileira vigente. Declaro ainda que fui informado que esta pesquisa foi previamente aprovada por um Comitê de Ética em Pesquisa (CEP) UniCEUB com Seres Humanos.

Todo o material da pesquisa ficará sob a guarda do pesquisador Italo de Oliveira durante um período de 5 anos após o término da pesquisa. A intervencão sera realizada no Labocien situada no $2^{\circ}$ subsolo do Centro universitario de Brasilia - UniCEUB 
Endereço: SEPN, 707/907, Via W 5 Norte - Asa Norte serão realizadas 24 sessoes, que correspondem a 8 semanas ou 2 meses de tratamento.

Se houver alguma consideração ou duvida referente aos aspectos éticos da pesquisa, entre em contato com o Comitê de Ética em Pesquisa do Centro Universitário de Brasília CEP/UniCEUB, que aprovou esta pesquisa, pelo telefone 3966.1511 ou pelo email cep.uniceub@uniceub.br. Também entre em contato para informar ocorrências irregulares ou danosas durante a sua partcipação no estudo.

Neste sentido, Eu, RG , após receber uma explicação completa dos objetivos do estudo e dos procedimentos envolvidos, manifesto minha concordância voluntária em fazer parte deste estudo.

Brasilia, de de

Testemunha

Pesquisador Responsavel

Orientador Responsavel

\section{CONTATOS}

Pesquisador: Italo de Oliveira (61)99223727

(italooliveirafsa@ghotmail.com)

Comitê de Ética: (61) 3966-1511

UniCEUB:

Endereço: SEPN 707/907 - Campus Asa Norte - Bloco 9
CONTATOS

Pesquisadora/ Orientadora: Leticia Martins

Paiva

(leticiamartins06@gmail.com)

Comitê de Ética: (61) 3966-1511

UniCEUB:

Endereço: SEPN 707/907 - Campus Asa Norte -

Bloco 9 
ANEXOS A - Parecer Consubstancial do CEP

\section{CENTRO UNIVERSITÁRIO DE Plotoforma BRASÍLIA - UNICEUB}

\section{PARECER CONSUBSTANCIADO DO CEP}

\section{DADOS DO PROJETO DE PESQUISA}

Titulo da Pesquisa: ELETROESTIMULAÇÃo NEUROMUSCULAR PARA FORTALECIMENTO DE RETO ABDOMINAL

Pesquisador: Letícia Paiva

Área Temática:

Versăo: 2

CAAE: 75055617.0 .0000 .0023

Instituiçăo Proponente: Centro Universitário de Brasilia - UNICEUB

Patrocinador Principal: Financiamento Próprio

\section{DADOS DO PARECER}

Número do Parecer: 2.497 .581

Apresentaçăo do Projeto:

- Objeto do estudo:

Amostra de 10 mulheres com fraqueza muscular do reto abdominal.

- Tipo de estudo:

Estudo descritivo e intervencional.

- Descriçăo dos participantes:

A amostra será composto por 10 voluntárias do sexo feminino, dividida em dois grupos: Grupo A: 5 Mulheres sedentárias que apresentam fraqueza muscular do reto abdominal; Grupo B: 5 Mulheres sedentárias que apresentam fraqueza muscular do reto abdominal pós-gestacional.

- Instituiçăo onde será realizado o estudo:

Centro Universitário de Brasilia - UNICEUB.

- Procedimentos com os participantes:

As participantes serăo submetidas à estimulaçăo elétrica neuromuscular (EENM) que é uma corrente de média frequência capaz de promover uma contraçăo muscular com finalidade de ganhar força e aumentar o volume muscular. Além da utilizaçăo da EENM será mensurado o índice de massa corporal (IMC), gordura abdominal através do adipômetro (\%G), força muscular através do teste de Kendal e nivel de desconforto através da Escala visual analógica (EVA).

- Instrumento de coleta de dados ou informaçōes:

Os dados coletados comporăo banco construído através da aplicaçăo do software EPI-INFO versão

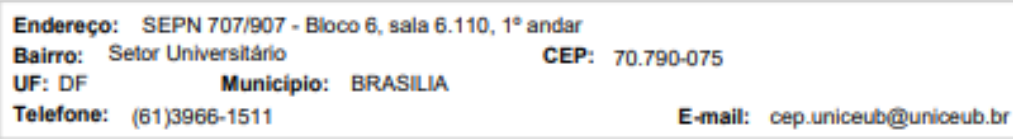




\section{CENTRO UNIVERSITÁRIO DE BRASILIA - UNICEUB}

Continuaçaso do Parecer: 2.497 set

\begin{tabular}{|l|l|c|l|c|}
\hline $\begin{array}{l}\text { Justificativa de } \\
\text { Ausência }\end{array}$ & TCLE.docx & $30 / 01 / 2018$ & ITALO DE OLIVEIRA & Aceito \\
\hline Outros & AVALIACAO.docx & $31 / 26: 13$ & & \\
& & $15: 48: 10$ & Leticia Paiva & Aceito \\
\hline Folha de Rosto & FOLHADEROSTO.pdf & $31 / 08 / 2017$ & Leticia Paiva & Aceito \\
& & $15: 46: 15$ & & \\
\hline
\end{tabular}

Situaçăo do Parecer:

Aprovado

Necessita Apreciação da CONEP:

Năo

BRASILIA, 16 de Fevereiro de 2018

Assinado por:

Marilia de Queiroz Dias Jacome

(Coordenador)

Endereço: SEPN 707/907 - Bloco 6, sala 6.110, $1^{\circ}$ andar

Bairro: Selor Universitário CEP: 70.790-075

UF: DF Municipio: BRASILIA

Telefone: (61)3966-1511

E-mail: cep.uniceub(g)uniceub.br 